\title{
Histomorphological and Histochemical Study of Macula Densa in Guinea Fowl (Numida meleagris) Kidney
}

\author{
Gajendra Singh*, Balwant Meshram and Hemant Joshi
}

Department of Veterinary Anatomy and Histology, College of Veterinary and Animal Science, Navania, Udaipur, Rajasthan, India

*Corresponding author

\begin{abstract}
A B S T R A C T
Keywords

Guinea fowl,

Macula densa,

Histomorphology,

Histochemistry and

Juxtaglomerular

apparatus

Article Info

Accepted:

10 October 2020

Available Online:

10 November 2020

The juxtaglomerular apparatus usually located at the vascular pole of nephrons, which comprises afferent and efferent arterioles along with a specialized form of cells known as macula densa. The elliptical-shaped macula densa originated from the convoluted part of distal tubule in a closely packed cellular mass. The macula densa is located at the exclusive spot stuck between afferent and efferent arterioles, wherein the salt concentration found with high variability. This macula densa believed to be performed as the renal sensor elements which could control many physiological functions like glomerular hemodynamic and renin secretion. Different staining procedures were employed while confirming different micro-morphological elements of macula densa. Different histoenzymic observations were also perceived during the attempt of present studies.

\section{Introduction}

The Macula Densa, a specialized cellular structure of distal tubules which believed to be performed important sensory function that transmit chemical signals in the juxtaglomerular apparatus while controlling different vital kidney functions, includes renal blood flow, glomerular filtration, renin release and the changes in tubular fluid composition (PetiPeterdi and Harris, 2010). The increase of sodium concentration in the tubular fluid leads to the decreased production of renin by extraglomerular mesangial cells and

juxtaglomerular cells (Maynard and Downes, 2019). Each of the renal corpuscle has two either side located urinary pole and vascular pole. The area where renal corpuscle initiate different parts of uriniferous tubules which known as urinary pole, however, the vascular pole has different parts of Juxtaglomerular apparatus viz. afferent and efferent arterioles and macula densa cells which are situated generally in between afferent and efferent arterioles (Ogawa and Sokabe, 1971). The darker stained rounded or elongated basal nuclei are evident at apical position with euchromatin and the nucleolus (Cangiotti et al., 2018).
\end{abstract}




\section{Materials and Methods}

A total of 12 pairs of Guinea fowl kidneys samples were collected and fixed in $10 \%$ Neutral Buffered Formalin and $5 \mu$ thick paraffin sections were obtained. Sections were stained with Haematoxylin and Eosin for general tissue reaction (Singh and Sulochana 1996), Silver orcein and Aniline blue method for elastic, reticular and collagen fibers (Singh and Sulochana 1996). The histochemical observations were perceived on paraffin sections after Periodic Acid Schiff s (PAS) and Alcian blue (AB) staining method for mucopolysaccharides (Singh and Sulochana 1996). The unfixed fresh samples were used for cryostat sectioning and performed staining procedure while knowing the activity of Succinic dehydrogenase (Singh and Sulochana 1996). The aforesaid stained sections were examined under the microscope and photomicrography was performed.

\section{Results and Discussion}

Microscopically the kidney of guinea fowl has shown mammalian and reptilian types of nephrons. The blood filtering units of nephrons were there in the form of renal corpuscles and each of which had urinary pole and vascular pole that were located opposite direction of each other. The urinary pole of renal corpuscle initiate uriniferous tubules and the vascular pole showed Juxtaglomerular apparatus with their different elements viz. afferent and efferent arterioles and the macula densa (Fig. 1, 2 and 3 ). These findings were by similar reports in avian kidney given by Sreeranjini (2010), Islam et al., (2004) and Singh et al., (2020 a). The mostly elliptical shaped macula densa was formed by closely packed tall and narrow cells with dark stained nucleus which had clearly visible lumen. These finding were comparable with Cazmir et al., 2008 and Casotti and Richardson, 1993).

The clump of 8-15 simple epithelium cells of macula densa was observed mostly at the center or sometimes at the corner of vascular pole and closely attached with the parietal epithelium of renal corpuscle i.e. Bowman's capsule (Fig. 1, 2 and 3). These findings were very similar with De la Peña and De Castro (1960) but partially similar with the revelations by Peti-Peterdi and Harris, 2010 and Mobini and Abdollahi, 2016 who has revealed the macula densa as a group of 15 to 20 simple tall columnar cells and the specialized tall simple cuboidal epithelial cells respectively, which was observed in vascular pole of the renal corpuscle.

Fig.1 Photomicrograph of Mammalian Renal Corpuscles Showing, Vascular pole (1), Macula densa (2), Urinary space (3), Condensation of cell nucleus (4), Lumen of macula densa (5) and Cell nucleus (6).H\&E-1000X




Fig.2 Photomicrograph Showing, Mammalian renal corpuscle, Macula densa (1), Distal convoluted tubule (2), Urinary space (3), Urinary pole (4) Vascular pole (5) and Condensation of cell nucleus (6).H\&E- 400x

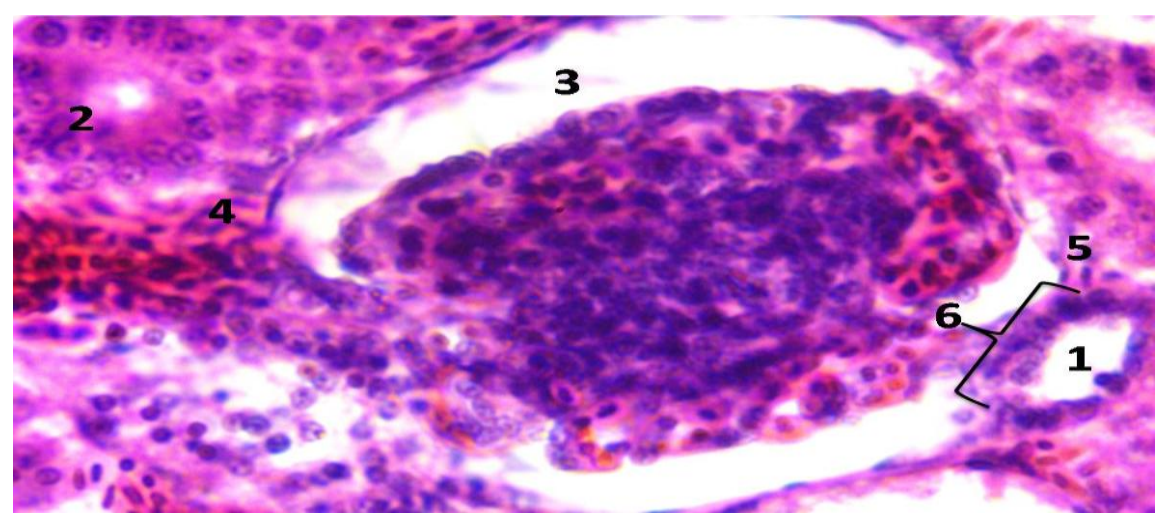

Fig.3 Photomicrograph of Reptilian Renal Corpuscles Showing different fibers in macula densa (1), Elastic fibers (Yellow arrow), Collagen fibers (Blue arrow) and Reticular fibers (White arrow) Silver orcein and Aniline blue- 1000x

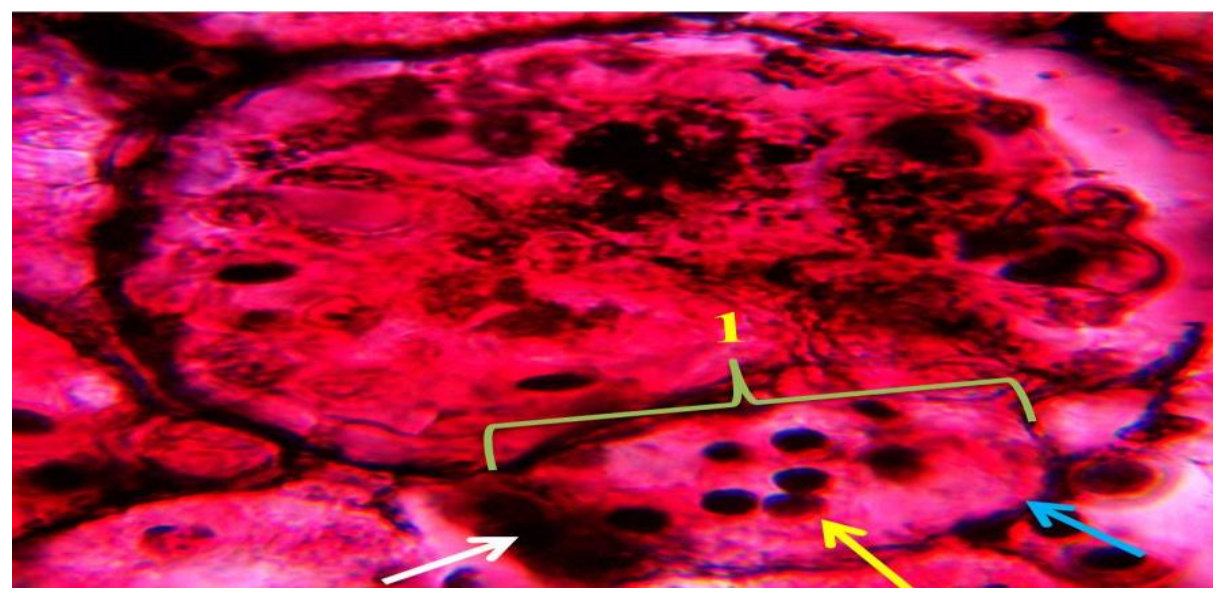

Fig.4 Photomicrograph Showing mucopolysaccharides in macula densa. Black arrow- Alcian blue positive PAS-AB-100X

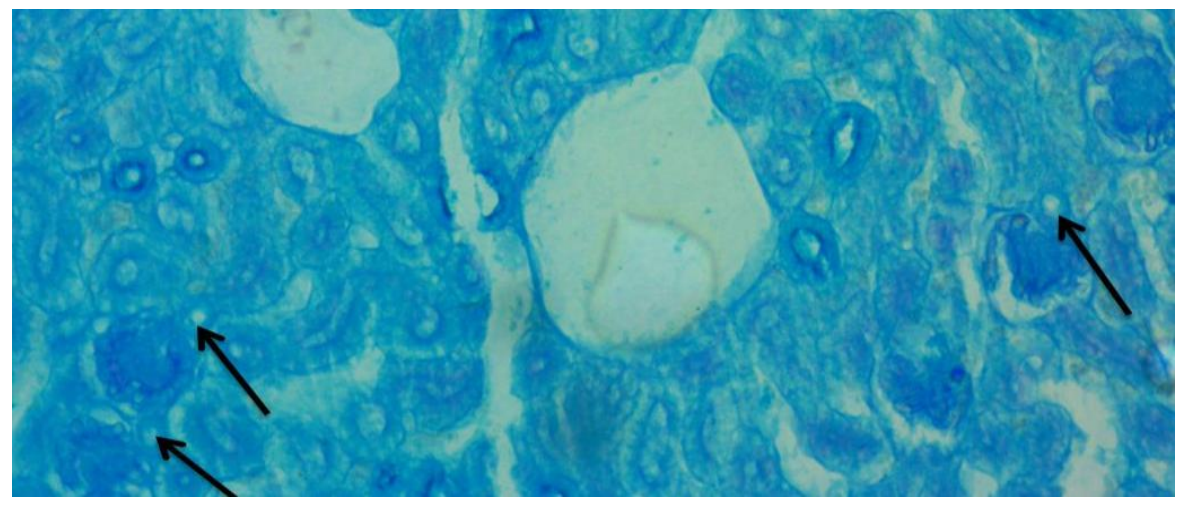


Fig.5 Photomicrograph Showing Histoenzymatic details of macula densa. Black arrow- Positive reaction in macula densa and Blue arrow- Feeble reaction in Renal corpuscle Succinic dehydrogenase- 100x



Silver orcein and Aniline blue stains were employed to know the extent of connective tissue fibers at macula densa, wherein, the elastic, collagen and reticular fibers were observed. However, the elastic fibers were discovered in predominant proportion in comparison with others but the collagen fibers were least in quantum (Fig. 3). The present findings were agreeing with the findings of Singh et al., (2020 a).

Periodic acid-Schiff (PAS) and Alcian blue (AB) ( $\mathrm{pH} 2.5)$ was used in attempt to determine neutral Mucopolysaccharides and acid mucopolysaccharide substances respectively. The cellular activity after Alcian blue was witnessed in the macula densa but the PAS has marked absence of activity there (Fig. 4). The present findings were partly agreeing with the mentionings of Grzycki, 1976 who has noted negative activity in the macula cells of Rat kidneys.

The enzymatic activity of Succinic dehydrogenase was observed in undertaken studies of macula densa (Fig. 5) which was fairly observed by Dhirender and Singh, 2011 in bats and strong activity was observed by Singh et al., $(2020$ b) in guinea fowl justifying higher mitochondrial content and thereby high oxidative potential in the tissue.

\section{References}

Cangiotti, A.M., Lorenzi, T., Zingaretti, M.C., Fabri, M. and Morroni, M. 2018. Polarized ends of human macula densa cells: ultrastructural investigation and morphofunctional correlations. The anatomical record, 301: 922-931.

Casotti, G. and Richardson, K.C. 1993. A qualitative analysis of the kidney structure of Honeyeaters (Meliphagidae) from wet and arid environments. Journal of Anat., 182: 239-247.

Cazmir, I., Cornila, M., Predoi, S., Marta, D. and Constantinescu, C. 2008. Histoand ultrastructural aspects concerning renal corpuscle in Coturnix Coturnix Japonica. Lucrari Stiintifice Medicina Veterinara, 41, 64-72.

De la Peña, A., and De Castro, F. 1960. Structure and arrangement of the macula densa in the human kidney. Urologia Internationalis, 10(3):171178.

Dhirender and Singh, S.P. 2011. Some observations on the alkaline phosphatase and succinic dehydrogenase activities in the juxtaglomerular complex and glomerulus of the kidney of $\mathrm{HgCl} 2$ - 
treated bat (Rhinopoma microphyllum). Biochemical and Cellular Archives, 11(1):183-185

Grzycki, S. 1976. Histochemical studies on macula densa cells in the juxtaglomerular complex of rat renin normal and experimental conditions. Zeitschrift fur mikroskopischanatomische Forschung, 90(3), 507513.

Islam, K. N., Khan, M.Z.I., Siddiqui, M.S.I., Islam, M.R., Lucky, N.S., Hossain, M.K. and Adhikary, G.N. 2004. The anatomical studies of the kidneys of Rhode Island Red and White Leghorn chicken during their postnatal stages of growth and development. International Journal of Poultry Science, 3(5): 369372.

Maynard, R.L. and Downes N. 2019. The Urinary Tract: Anatomy and Histology of the Laboratory Rat in Toxicology and Biomedical Research, Chapter 17 Pp. 197-206 Academic Press, Elsevier Inc.

Mobini, B. and Abdollahi, M. 2016. Effect of sex on histological and histochemical structures of different parts of the kidney in Japanese quail (Coturnix japonica). Journal Poultry Science
$0: 1-6$.

Ogawa, M. and Sokabe, H. 1971. The macula densa site of avian kidney. Z. Zell forsch., 120: 29-36.

Peti-Peterdi, J. and Harris, R. C. 2010. Macula densa sensing and signaling mechanisms of renin release. J Am Soc Nephrol., 21(7): 1093-1096.

Singh UB, Sulochana 1996. Handbook of histological and histochemical techniques, Premier Publishing House, Hyderabad,

Singh, G., Joshi, H. and Meshram, B. 2020 a. Histological study on the kidney of guinea fowl (Numida meleagris). Online International Interdisciplinary Research Journal, 10 (3): 10-22.

Singh, G., Joshi, H. and Meshram, B. 2020 b. Different histochemical observations on the kidney of guinea fowl (Numida meleagris). Journal of Entomology and Zoology Studies, 8(2): 1716-1719.

Sreeranjini, A.R., Iyyangar, M.P. and Kumar, P.D. 2010. Histological study on the fibrous architecture of kidney and ureter of Japanese quail (Coturnix Coturnix Japonica). Tamilnadu J. Veterinary \& Animal Sciences, 6(2): 107-110.

\section{How to cite this article:}

Gajendra Singh, Balwant Meshram and Hemant Joshi. 2020. Histomorphological and Histochemical Study of Macula Densa in Guinea Fowl (Numida meleagris) Kidney. Int.J.Curr.Microbiol.App.Sci. 9(11): 978-982. doi: https://doi.org/10.20546/ijcmas.2020.911.116 